\title{
Un flequer bandejat: edició i estudi lingüístic d'un procés criminal valencià de l'any 1578
}

\author{
Joan Barberà i Ibiza ${ }^{1}$
}

Recibido: 5 de marzo de 2018 / Aceptado: 15 de octubre de 2018

Resum. Presentem ací l'edició i l'anàlisi lingüística d'un procés criminal de la localitat de Sueca, datat el 1578, el qual ens narra com un flequer és sorprés de nit en la sala on es guardava el gra de la localitat. Hem seleccionat les declaracions de l'inculpat i dels testimonis, l'escrit de defensa i el fragment de sentència en què se'l declara culpable de robatori. Se li imposa una pena de dos anys de bandeig.

Paraules clau: processos criminals; edició de textos; Decadència cultural i lingüística; anàlisi lingüística.

[en] A banished baker: editing and linguistic study of a Valencian criminal process of the year 1578

\begin{abstract}
The edited and analyzed text is a criminal process in the town of Sueca, dated in 1578, which tells us how a baker is surprised at night in the room where the grain of the town was stored. We have selected the accused and the witnesses's declarations, the defense document and the sentence fragment in which he is found guilty of robbery. He is sentenced to two years of banishment.
\end{abstract}

Key words: criminal processes; text editing; cultural and linguistic decadence; linguistic analysis.

Sumario. 0. Introducció, 1. El text: descripció, 2. Anàlisi lingüística., 2.1. Grafies, 2.2. Fonètica, 2.3. Morfosintaxi, 2.4. Lèxic, 2.5. Conclusions, 3. El text: l'edició, 4. Bibliografia

Cómo citar: Barberà i Ibiza, J. (2019). Un flequer bandejat: edició i estudi lingüístic d'un procés criminal valencià de l'any 1578, en Revista de Filología Románica 36, 9-32.

\section{Introducció}

El text seleccionat és un procés criminal de l'any 1578 que pertany a la localitat valenciana de Sueca. Aquesta localitat està situada a trenta quilòmetres i escaig al sud, en línia recta, del cap-i-casal valencià. Per tant, si bé durant aquest període esdevé una localitat merament agrícola dedicada al cultiu de l'arròs, no resta aliena al període d'expansió demogràfica i econòmica que afecta el País Valencià a partir de la segona

\footnotetext{
Generalitat de Catalunya. Departament d'Educació jbarbera1980@gmail.com
} 
meitat del cinc-cents (Ardit, 1992: 142-152). De fet, durant l'Edat Moderna, a Sueca, 1'extensió de terra d'arròs cultivada va créixer espectacularment. ${ }^{2}$

Quant al gènere textual, som davant d'un document de caire judicial, ja que es tracta d'un judici per robatori. Hem de tenir en compte que, durant el període tractat, som en plena Decadència de la llengua i la cultura catalanes, de manera que aquests tipus de texts esdevenen força útils per a estudiar-les; els relats duts a terme pels escrivans ens ofereixen una informació força valuosa tant pel que fa a la llengua com per tot allò que al·ludeix al mode de vida de l'època. Així doncs, si ens centrem en el contingut del manuscrit, observem com l'inculpat és sorprés pel justícia ${ }^{3}$ de Sueca dins d'una sala on es guardaven diferents quantitats de gra. A més, troben en el seu poder una clau falsificada que li permet obrir la porta de la dita sala. L'inculpat argumenta que la clau no és seua i que no ha entrat a furtar, ans que va veure la porta oberta $\mathrm{i}$ entrà a orinar. També presenta tota una sèrie de testimonis favorables que donen fe de l'honradesa d'aquest. No obstant, el fet d'haver trobat en el seu poder una clau falsificada i que un testimoni desmunte la coartada presentada, esdevé determinant perquè siga declarat culpable: és condemnat a dos anys de desterrament $\mathrm{i}$ a dues multes. Observem-hi, tot seguit, el fragment transcrit de la sentència:

[29R] [...] lo condempna con desterro y exhili del present loch y tot lo terme de Çueca per temps y espay de dos anys a beneplàcit emperò de la il·lústríssima señoria y que no puixa entrar en los dits terme e loch de Çueca durant [los] dits dos anys y en contravenció de bandech [...] attrobat serà, haver contravengut ad aquell lo dit Joan Navarro, ara per llavós y llavós per [ara] lo condempna en cent liures reals de València applicadores als cófrens de dita il·lústríssima señoria e, axí mateix, lo condempna en pena de quaranta liures de la dita moneda [...].

\section{El text: descripció}

El manuscrit seleccionat, 1'hem localitzat a 1'Arxiu Històric Municipal de Sueca (AHMS) amb la signatura 101-61. Pel que fa als fulls escollits, a banda del fragment de sentència anteriorment transcrit (29R), hem editat les parts del text que es corresponen amb les declaracions de l'inculpat i dels testimonis. També hem considerat que l'estat del manuscrit ens permeta seguir el relat amb fluïdesa. A més, transcrivim l'escrit de defensa, car ens ofereix el relat sencer de la història, malgrat que ho fa de manera parcial, òbviament. Consegüentment, hem editat els següents fulls i intervals: 1R, (portada), 4R-5v, 11R-16V i 17R-20R.

Quant a l'estat d'aquests, el pas del temps ens ha deixat la seua petjada: alguns fulls presenten petits fragments trencats o esborrats. Nogensmenys, gran part d'aquests encara els hem pogut transcriure amb fidelitat a l'original (el trencament o l'esborrament esdevenen parcials); aquests tipus de fragments, els hem transcrit entre claudàtors. Els fragments irrecuperables els identifiquem amb tres punts entre claudàtors. La resta de criteris d'edició es corresponen amb les normes de la col·lec-

Aquest augment és produeix gràcies al terreny que se li va guanyar a l'Albufera mitjançant la dessecació del llac (Furió, 1982: 10).

3 El càrrec de justícia esdevé una figura pròpia del dret foral valencià, la qual s'encarregava de realitzar tasques judicials i del manteniment de l'ordre públic a nivell municipal. 
ció Els nostres clàssics, criteris prototípics en l'edició de textos medievals i moderns catalans.

\section{Anàlisi lingüística}

\subsection{Grafies}

Quant a les grafies, primerament, cal remarcar l'encreuament gràfic català - castellà que es produeix en la representació del fonema nasal palatal, car hi documentem tres tipus de representacions fruit d'aquest encreuament: el dígraf autòcton català $n y$, la forma castellana $\tilde{n}$ i l'encreuada $\tilde{n} y$ : anys (4R), pañy (4V) o señor (1R.)

Durant el segle XVI, la presència de la grafia castellana no sols el documentem en textos valencians, ans que també el podem trobar en textos eivissencs (Veny, J.; Màssip, À. 2009:120).

A més, també podem destacar-hi l'ús de la $-\mathrm{h}-\mathrm{amb}$ valor antihiàtic per marcar una apòcope consonàntica en termes com ara, crehensa $<$ CREDENTİA $(15 \mathrm{~V})$ o rahó $<$ RATIONE (14V).

Pel que fa a la representació del so africat palatal sord, aquest també apareix representat amb la grafia -ch- en diversos termes, com ara porche (14V). No obstant això, aquesta grafia no sols representava el fonema citat anteriorment, sinó que, en posició final, encara representava el so oclusiu velar sord, tret prototípic de la representació gràfica catalana general: amich (17R), descàrrech (14R), lloch (1R). De fet, en determinats mots es manté aquesta grafia quan s'afegeix el morfema -s per formar el plural: magnifichs (11R).

\subsection{Fonètica}

Primerament, pel que fa al vocalisme tònic, cal remarcar la controvèrsia que es produeix entre les formes sent / sant, ja que l'estabilitat dels sons vocàlics en posició tònica no afavoreix els canvis. Així doncs, pel que fa a aquest canvi, de les diferents hipòtesis exposades per distints autors (Martí Mestre, Vol.: II, 1994:77; Veny, 2009:114-128) considerem més probable l'exposada per J. Veny, car la posició proclítica del terme provoca que aquest perda la tonicitat i esdevinga susceptible al tancament $\mathrm{a}>\mathrm{e}$. Quant a la presència quantitativa d'aquestes formes en el nostres text, s'hi dona una proporció $70 \%-30 \%$ a favor de les formes amb -e-.

Nogensmenys, hem de remarcar que en l'actualitat en el parlar de la localitat estudiada la forma que ha esdevingut predominant és l'etimològica sant. Pressuposem que la influència del castellà en l'evolució del valencià ha pogut ajudar a aquest fet.

En relació amb el vocalisme àton, primerament remarcarem el pas e $>$ a de la forma flaquer. Aquesta forma no era única de la localitat de Sueca, sinó que també la documentem en unes altres localitats de la Ribera del Xúquer, com ara Alzira (Barberà 2018:219-220).

A més, també cal destacar l'ús de la forma desculpar; cataloguem aquesta forma com a col·loquial, car s'ha produït una modificació del grau d'obertura de la vocal inicial (dis $>$ des) respecte de l'ètim llatí, Disculpare. De fet, les formes configurades amb el prefix des- resultaven habituals en aquest context, puix que 
en trobem en uns altres textos contemporanis de localitats properes a l'estudiada (Barberà 2018:222).

Pel que fa al so o/u en posició àtona, malgrat que el valencià, com tots els dialectes occidentals (Badia i Margarit, 1994[1951]:119-120), sí que distingeix aquests sons en posició àtona, trobem una sèrie de termes en què es produeix el pas $\mathrm{o}>\mathrm{u}$ en posició àtona: primerament, podem fer referència al participi uberta $(4 \mathrm{~V})$ en el qual observem el pas o > u en posició pretònica inicial. Segons Joan Veny (2015:27), aquest és conseqüència de la influència d'infinitius com ara *ubrir, els quals assimilen el grau d'obertura de la vocal inicial al de la tònica. No obstant, no podem descartar la influència del terme cubert, en el qual el pas o $>\mathrm{u}$ el podem atribuir al contacte amb la velar inicial. A més, també trobem el nom propi Juan; en aquesta forma el pas o $>$ u pot ser conseqüència del contacte amb la palatal inicial. També cal fer referència a la presència del diftong creixent [wa] en els numerals quaranta i quatorze. Quant a la primera forma, entenem que esdevindria la pronúncia normal de l'època, car la forma actual monoftongada [wa] $>0$, coranta, no és documentada per fonts com el CICA o el CIVAL fins al segle XVII. En canvi, la forma quatorze podem pressuposar que es tracta d'un arcaisme emprat en la fórmula jurídica documentada, ja que l'ús de la forma catorze ja era ben viu i consolidat durant l'època estudiada. ${ }^{4}$ Tampoc no hem descartar que l'escrivà represente el so oclusiu velar sord amb la grafia qu-. A més, també cal referir-se a la presència del grup -ie-, en el terme quietut (19V), ja que en el parlar actual ha quedat reduït a-e-perquè la vocal àtona del terme del qual deriva, quiet, ha assimilat el grau d'obertura de la tònica (-ié- $>$ -eé- $>$-é-). Consegüentment, el terme configurat amb el sufix-etud esdevé quetud.

En relació amb el consonantisme, podem destacar diversos trets, com ara la representació de la nasal alveolar final en posicions en què hauria d'estar emmudida: aquest és el cas dels numerals onzén (12R) i quatorzén (12V), i el demostratiu pronominal axín (16R). Quant als dos primers, si analitzem el context, la posició proclítica d'ambdós pot haver afavorit aquest fenomen:

12R [...] sobre lo onzén capítol de la dita scriptura obmesos los precedents, etc.: [...].

12V [...], sobre lo quatorzen capítol de la dita scriptura obmesos los precedents, etc.: $[\ldots]$.

De fet, el manteniment de la nasal final en termes que, teòricament hauria d'estar emmudida, és un fenomen que en català també es dona en altres expressions, com ara man dreta (Barberà, 2018:246-247).

En referència al demostratiu, el fet que, hui dia el valencià general, haja conservat la forma femenina aixina pot haver ajudat al manteniment d'aquesta nasal final. Observem-hi l'exemple documentat:

16R [...] e axín requir e demana ell, [...].

A més, dins de les nasals, cal remarcar el pas $\mathrm{N}>\mathrm{M}$ en el nom propi Micolau $(11 \mathrm{~V})$. Aquesta variant, imaginem que més pròpia dels registres col·loquials, no era exclusiva de la localitat documentada, sinó que també la trobem en altres localitats properes, en textos contemporanis (Barberà, 2018:246). Pel que fa als seus orígens,

Vegeu CIVAL, catorze. 
F. de Borja Moll (2006 [1952]:107) proposa un encreuament amb un altre nom propi, com ara Miquel.

En relació amb les oclusives, destacarem dos fenòmens: primerament, podem observar l'ensordiment de la dental final en els terme recort $i$ quietut. Aquest es pot deure a un fenomen prototípic del valencià central, com és l'ensordiment de les oclusives finals. En segon lloc, trobem la sonorització interior [k] > [y], en la forma regonegué. Hem de deixar clar que les formes del verb reconéixer amb -g-interior esdevenen pròpies del valencià de l'època medieval i moderna, tal com podem observar en el CIVAL. ${ }^{5}$

Pel que fa als grups consonàntics, podem destacar la presència del grup inicial SC-, en mots com ara scriure (11V) o scriptura (11R). També cal remarcar la presència del grup culte interior-NCT- del terme junct $(15 \mathrm{~V})$.

\subsection{Morfosintaxi}

Primerament, pel que fa a la morfologia flexiva, cal remarcar la presència del morfema -o com a marca de masculí singular en els adjectius $i l \cdot l u s t r i ́ s s i m-o$ i bonic-o. En el primer cas, el terme sencer podria tractar-se d'un castellanisme lèxic, car s'hauria pogut copiar la forma de cortesia sencera del castellà. No obstant, el segon cas, el podem catalogar com un castellanisme morfològic, puix que en català les formes amb la flexió de gènere i nombre anomenades presenten morfema buit.

Quant a les formes derivades, farem referència als diminutius fill-eta (4R) i entrad-eta $(14 \mathrm{~V})$, emprats per fer referència a una filla de l'inculpat i a l'entrada de la cort local, respectivament. Hem de remarcar que, en l'actualitat, el valencià és un dialecte que es caracteritza per l'ús abusiu de diminutius. D'altra banda, també cal citar el terme quietut (19V) el qual es forma a partir de l'adjectiu quiet i el sufix derivatiu - etud, emprat per formar substantius a partir d'adjectius.

Un altre aspecte que cal remarcar és l'ús dels possessius, car hi trobem dues característiques remarcables: primerament, podem parlar de l'ús dels possessius àtons; malgrat que en el context estudiat, hui dia, han quedat reduïts a expressions de l'àmbit familiar (ma mare, mon cosí, ma casa...), en el text estudiat, el trobem vinculat a un major nombre de contextos. Vet ací els distints exemples documentats, en els quals observem com sols hi ha una mostra referida a l'àmbit familiar (sa casa), la qual es repeteix cinc vegades:

sa (9v.)

4V $[\ldots]$ e anar-se'n a sa casa.

14R $[\ldots]$ fiscal tinga provada sa intenció $[\ldots]$.

14R [...] proposant en sa condició, [...].

15V $[\ldots]$ no havent produhit per sa part $[\ldots]$.

16R $[\ldots]$ en sa persona objectes molt nottoris, $[. .$.$] .$

son (1v.)

14R $[\ldots]$ y per a donar son descàrrech y desculpa $[\ldots]$.

$\operatorname{sos}(2 \mathrm{v}$.

Vegeu CIVAL, regonéixer. 
$4 \mathrm{~V}[\ldots]$ e fer sos fets.

18R [...] que tracta sos negocis ab molta fidelitat y sens frau.

També trobem mostres de les formes antigues i etimològiques sua > SUAM (14R) i sues >SUAS (5R); en l'actualitat han estat substituïdes per la formes seua i seues respectivament, de les quals no hem trobat cap mostra. Aquestes formes modernes es configuren a partir del masculí seu i els morfemes -a / -es com a marques de femení singular / plural (GNV, 2006:136).

14R Davant la presència del magnífich justícia del present lloch de Çueca y en cort sua comparegué personalment.

5R Fonch interrogat si són aquestes les sues [...].

Quant als demostratius, si bé durant aquest període la separació dialectal entre els demostratius simples i reforçats comença a consolidar-se (Farreny, 2004:247), en el nostre text únicament trobem la forma reforçada aquestes (5R). Aquest fet esdevé contrari a la divisió dialectal actual. Podem atribuir aquest fet al context en què la trobem; no forma part del relat dels testimonis, sinó que apareix en una expressió prototípica d'aquests tipus de textos. Aquest fet justifica l'ús de la forma reforçada en lloc de la simple. Vet ací l'exemple:

5R-V Fonch interrogat si són aquestes les sues conffessions y judicials respostes: E dix que sí.

Tanmateix, durant aquest període, amb tota probabilitat, ambdues formes encara s'emprarien de manera conjunta en el context estudiat, tal com s'explica en estudis referits a localitats properes de la mateixa època (Barberà, 2018:293-296).

En relació amb la morfosintaxi verbal, primerament, farem referència als perfets forts dix (4R) i fonch (4R). L'evolució del llatí vulgar al català ha configurat dos tipus de perfets: forts o tònics (presenten l'accent fonètic en el lexema) i febles o àtons (de manera contrària als anteriors, presenten l'accent fonètic en la desinència). Així doncs, pel que fa a la forma dix, pressuposem que aquesta esdevé un arcaisme cenyit al registre jurídic, car sempre apareix documentada en la construcció e dix que, forma prototípica emprada pels escrivans per començar a recollir les declaracions dels testimonis i dels inculpats. ${ }^{6}$ De fet, el CIVAL ja documenta les primeres mostres de la forma digué en textos valencians des de finals del XIII i principis del XIV, ${ }^{7}$ fet que corrobora la nostra suposició. Pel que fa a la forma fonch, aquesta també forma part d'una expressió típica del registre judicial fonch interrogat, de manera que no hem de descartar que en la parla viva del context estudiat s'empraren amb major freqüència les formes fon i fou, malgrat que no les hem documentades en el nostre text, actualment. Actualment, en la localitat estudiada, la forma perifràstica va ser ha substituït les formes anteriorment citades.

Un altre aspecte que podem remarcar en el terreny de la morfosintaxi verbal són les desinències d'imperfet de subjuntiu en -er. Actualment, esdevenen una de les

6 En el nostre text documentem un total de setanta-dos exemples d'aquesta construcció. De fet, totes les vegades que ens trobem amb la forma verbal dix, ho fem en l'expressió citada.

Vegeu CIVAL, digué. 
isoglosses que separen el valencià del nord-occidental (Massanell; Veny, 2002:49, mòdul III) $\mathrm{i}$ un dels trets privatius del valencià com a variant dialectal diferenciada. El seu origen cal cercar-lo en l'anivellament dels temps verbals en els oracions condicionals hipotètiques o irreals causat per la influència del castellà (Pérez Saldanya, 1998:305-306). Així doncs, podem observar distints exemples en els quals les formes de la pròtasi en imperfet de subjuntiu i plusquamperfet de subjuntiu presenten ja morfemes amb-er:

\section{imperfet de subjuntiu}

$18 \mathrm{~V}[\ldots]$ e que no folgara que lo dit Colàs Assenssi tinguera enuig [...].

\section{plusquamperfet de subjuntiu}

15V si lo dit proposant haguera portat la dita clau faytisca per a obrir les portes de la dita cort [...] que haguera llançat en terra la dita, puix li era fàcil al dit proposant llançar-la. 19R [...] que si alguna cosa haguera faltat ho haguera hoït dir ell, [...].

20R [...] si haguera faltat que ell, dit testimoni, ho haguera hoït dir, per tenir ell, dit testimoni, sa casa e habitació en lo dit e present lloch de Çueca.

De fet, l'anivellament es produeix gràcies a la presència d'aquests tipus de condicionals, pròpies de la llengua antiga, les quals esdevenen hereves directes del plusquamperfet d'indicatiu llatí (Bernat; Martí; Massanell; 2000:120). Aquest seria el cas de la forma folgara exposada en l'exemple anterior.

Un altre aspecte que cal remarcar en la relació als usos verbals és l'ús del verb ésser com a auxiliar en construccions sense complement directe (CD). Segons Mar Batlle (2002:24) l'ús d'aquest com a auxiliar es va mantindre força viu fins al segle XVIII, període en què el seu va sofrir un fort declivi. Hem de remarcar que l'ús d'aquest verb com a auxiliar no és exclusiu del català, ans que ha esdevingut un recurs prototípic de les llengües romàniques; actualment, l'italià i el francés també li confereixen aquesta funció (Mateu, 2005:212). Consegüentment, a partir d'aquests estudis i de la nostra documentació, podem deduir que les construccions formades amb el verb ésser com a auxiliar sí que serien emprades en la Sueca del darrer terç del setze. Observem-hi tota una sèrie de mostres de l'ús d'aquesta construcció recollides en el relat de les declaracions dels testimonis:

4V E dix que, havent pus de quinze dies que ell, dit conffessant, no era exit de casa, [...].

$11 \mathrm{~V}[\ldots]$ en lo pañy del cadenat de dita porta era estada attrobada una clau, [...].

$11 \mathrm{~V}[\ldots]$ lo dit Juan Navarro és estat attrobat de nit, [...].

$17 \mathrm{~V}[\ldots]$ E primerament és estat interrogat ell, [...].

D'altra banda, també cal remarcar distints aspectes vinculats a unes altres categories gramaticals, com ara els adverbis, les preposicions i les conjuncions. Quant als primers, cal destacar les formes temporals enans, llavors i vespre perquè en l'actualitat no són formes emprades en el context estudiat. Les dues primeres han estat substituïdes pels castellanismes antes i entonces i el concepte de vespre com a part del dia ha estat desplaçat per la locució «a poqueta nit». També és interessant remarcar l'ús del quantitatiu pus (més), car en l'època documentada, si tenim en compte 
les diferents datacions que ens ofereix el CICA, ${ }^{8}$ podria tractar-se d'una forma en retirada o també podria esdevenir ja un arcaisme.

En relació amb les preposicions, hem de fer referència a l'ús de les formes des de que, per a, sens i ultra. Quant a la primera, podem observar com, de manera contrària a la normativa actual, la forma de es manté per davant de la conjunció que en aquesta construcció. En relació a la segona, podem observar l'ús sistèmic del a preposició per a per davant de clàusules subordinades d'infinitiu amb valor final. Emili Casanova (1989:187-201) demostra la genuïnitat d'aquesta forma. Pel que fa a la forma sens, cal remarcar que, actualment, en el context estudiat, sempre s'utilitza amb la vocal final de suport -e (sense). Darrerament, destacarem la presència de la forma ultra, la qual entenem que no forma part del parlar popular, ans que era un llatinisme incorporat a un text jurídic.

Pel que fa a les conjuncions, podem destacar la presència de les formes coordinades $e$ i eo. Aquesta segona, segons G. Colon (Apud Casanova, 2008:70) podria derivar de l'expressió llatina is ea id. També hem de fer referència a la construcció explicativa per ço, la qual actualment ha estat substituïda per la forma per això. En darrer lloc, hem de fer referència a la forma per a que; si quan parlàvem de les preposicions la forma per $a$ introduïa clàusules subordinades d'infinitiu amb valor final, per extensió, és normal que aquesta s'encreuara amb la forma perquè i originara la construcció per a que (Barberà, 2018:443).

\subsection{Lèxic}

Oferim ací una mostra de termes recopilats pel seu interés lingüístic, tant per l'aspecte diacrònic com pel diatòpic. Els hem classificat alfabèticament amb la forma normalitzada o sense flexionar en gènere $i$ nombre, malgrat que en alguns casos també oferim el terme amb la grafia documentada entre claudàtors. ${ }^{9}$ També hi donem una petita definició de la paraula recollida i oferim entre parèntesi la font de la qual 1'hem extreta. Les obres lexicogràfiques que hem emprat per realitzar aquest apartat han estat el Diccionari Català-Valencià-Balear (DCVB), el Diccionari Etimològic $i$ Complementari de la Llengua Catalana (DECat) i el Diccionari Normatiu Valencià (DNV).

Abonat (14R): Bo, bondadós. (DCVB, DNV)

Afidat [Affidat] (14R): Persona mereixedora de confiança. (DCVB)

Cappatró [capatrons] (5R): Llibre de registres. (DCVB, DNV)

Casatinent (19R): Persona que té una casa en propietat i és cap de família. (DCVB, DNV)

Clamater [clamaters] (14V): Querellant. (DCVB)

Conteste (15V): Testimoni que confirma una declaració anterior. (DCVB)

Cort (1R): En la nostra transcripció presenta distints sentits. D'una banda, fa referència al tribunal i d'altra esdevé sinònim de sala. Quant al segon sentit, per tot el que es diu al llarg del text, entenem que era la sala on es reunien els jurats de la vila i també es guardava el gra. (DCVB)

Vegeu CICA, pus.

9 Com es pot comprovar, en alguns casos no cal emprar aquest criteri; la paraula ja està escrita al manuscrit de manera que es correspon amb les grafies actuals. 
Denunciació (1R): Denúncia. Acte de denunciar. (DCVB, DNV)

Eixir [exir] (14V): Sortir. En l'actualitat aquesta forma està pràcticament restringida al País Valencià, malgrat que antigament era d'ús general arreu del sistema lingüístic. (DECat) Estona (15R): L'interés d'aquesta forma rau en el fet que, actualment, en el valencià col·loquial ha estat substituïda pel castellanisme rato. Nogensmenys, encara la trobem documentada en la Sueca del 1578.

Faitisca (12R): Falsificada. (DCVB, DECat)

Fatiga (19R): Tardança a complir una obligació. (DCVB)

Llaurador (16V): Al País Valencià, persona dedicada als treballs agrícoles i del camp. (DCVB)

Morisc [morisca] (12V): En el nostre text, persona musulmana que ha estat batejada. (DCVB, DNV)

Notari (1R): En la nostra transcripció actua com a sinònim d'escrivà, és a dir, qui tenia la potestat de transcriure i/o copiar escrits jurídics i legislatius, i en donava fe. (DCVB)

Oficial [officials] (5R): Segons el sentit del nostre text, encarregats públics de tancar la sala municipal en què es guardava el gra, els llibres de la vila...(entre altres funcions, pressuposem).

Oró (11R): Cabàs, que sol ser més gran que ample, destinat a guardar-hi gra, llegums, fruits sec. També pot referir-se a una mena de dipòsit rectangular o cilíndric situat als racons de les algorfes. (DCVB, DNV)

Torbat (4V): En el nostre text es correspon amb el sentit de pertorbar l'ànim. (DNV)

$\operatorname{Ver}(14 \mathrm{R})$ : Vertader. (DCVB, DNV)

\subsection{Conclusions}

Realitzat aquest comentari lingüístic, podem remarcar que la llengua de la Sueca del darrer terç del segle XVI es tracta d'un parlar que presenta tant trets de la llengua antiga com pinzellades del català modern; si bé trobem elements propis del català antic, comencen ja a perfilar-se, o a fer-se paleses de forma evident, les característiques que hui dia defineixen el valencià com a dialecte dins de la llengua catalana.

Com a característiques conservades de la llengua antiga, podem citar l'ús de formes amb el prefix des- en lloc de dis-, tal com ocorre en la forma desculpar, la sonorització de l'oclusiva velar en posició interior del terme regonegué, la presència del grup culte interior -NCT- en el terme junct, l'ús estés dels possessius àtons, la utilització del verb ésser com a forma auxiliar dels temps compostos i la presència d'adverbis com ara enans i pus.

Quant a les característiques que defineixen el valencià hem de fer referència la presència de formes d'imperfet $i$ de plusquamperfet de subjuntiu amb els morfemes amb -er, l'ús de la preposició per a i per extensió de la conjunció per a que per da- 
vant de clàusules subordinades finals d'infinitiu i la presència de formes lèxiques que actualment esdevenen prototípiques valencianes, com ara llaurador i eixir.

Finalment, un altre aspecte al qual cal fer referència és a la presència de trets propis del castellà, com ara l'ús de la grafia $\tilde{n}$ o de la forma encreuada $\tilde{n} y$ o la presència del morfema - o com a marca del masculí singular en la forma bonico. Tanmateix, malgrat el pes que el castellà té en la configuració del valencià com a dialecte i la importància social que aquesta llengua guanya al segle XVI a partir de la derrota dels agermanats, no observem que el seu pes siga determinant en els textos estudiats.

\section{El text: l'edició}

[1R] Denunciació.

Procés del honorable en Juan Avellà, procurador fiscal del il·[1ustríssimo] señor mestre de Muntesa en lo present lloch de Çueca, contra: En Juan Navarro, flaquer del dit 1l[och] [...].

Scrivà: Joan Batiste Lledó, notari.

En la Cort de Çueca.

\section{[4R] Conffessions ex officio rebudes en lo lloch de Çueca.}

Die XXVIII ${ }^{\circ}$ mensis decembris anno a nativitate Domini MLXXVIII.

En Juan Navarro, conffessant, lo qual, iuxta forma fori jura, etc., dir veritat, etc.

[E] [prim]erament és estat interrogat com se nom[ena]:

[E dix q]ue Juan Navarro.

Fonch interrogat de quina edat és:

[E dix] que de edat de quaranta anys poch m[és o menys].

Fonch interrogat quin offici té:

E dix que és flaquer.

Fonch interrogat si té casa, muller, fills e famíl[i]a en lo present 1loch:

E dix que té casa, muller e família en lo present 11[och], e una filleta de poca edat.

Fonch interrogat si usa del dit offici de flaque[r]:

E dix que sí. $[\ldots]$ :

Fonch interrogat si és estat moltes vegades [...] eo en la cort del present $11 \mathrm{o}$ [ch]

[4V] E dix que algunes vegades és estat citat per alguna persona o que ell, dit testimoni, haja citat a alguna persona.

Fonch interrogat quant temps ha que no és estat en dita sala eo cort:

E dix que haurà dos mesos, poch més o menys.

Fonch interrogat si era de nit o de dia:

E dix que de dia, a hora de cort.

Fonch interrogat ell, dit conffessant, que tenia que [...] despús-anit vespre en dita sala eo cort:

[E dix] que, havent pus de quinze dies que [ell], dit conffessant, no era exit de casa, dettermi[nà] [...] vespre, que era la nit del gloriós sen[t] [Estheve] a passejar. $\mathrm{E}$, posant-se davall lo [...] [d]e la dita sala eo cort, véu ell, dit conff[essant], que la porta 
estava uberta. E axí ell, dit c[onffessant], detterminà de entrar dins a orinar e fer sos fets. E estant que volia tancar ell, dit confessant, la dita porta, attrobà que en lo pañy hi havia una clau e lo dit magnífich justícia vingué en lo [...]. E ell, dit conffessant, se trobà molt torbat de veure que lo dit magnifich justícia lo havia trobat, que no féu sinó deixar lo dit magnifich justícia e anar-se'n a sa casa.

Fonch interrogat per quina causa s'enportà la dita clau a sa casa.

[E] dix que ell, dit conffessant, la s'enportà a $[\ldots]$ [5R] de donar-la a Colàs Assenssi, missatge del present lloch.

Fonch interrogat per quina causa dix que lo dit Colàs Assenssi li havia acomanat la dita clau a el[1], dit conffessant:

E dix que lo dit Colàs Assenssi no li ha acomanat la dita clau ni està en recort que tal haja dit.

Fonch interrogat si sab o ha vist ell, dit confessant, que en dita sala y hajen acostumat tenir los officials del present lloch forment o altres grans:

E dix que ell, dit conffessant, no havia vist ni sab [...] sala y haja hagut ni de present y [...] forment ni altres grans.

Fonch interrogat si sab o ha vist o hoït [...] sala estigueren dos armaris en lo [...] los llibres e registres de la cort de [...] justícia e en lo altre los capatrons, llibres, registres de la universitat del present lloch:

E dix que no y sab res.

Fonch interrogat per quina causa donà e[11, dit] conffessant, la dita clau al dit magnífich justícia e a hon li donà e lliurà aquella:

E dix que ell, dit conffessant, li donà la dita clau al dit magnifich justícia en la plaça del present lloch per a que la donàs al dit Colàs Assenssi, missatge, lo mateix instant e aprés se n'anà a sa casa.

Fonch interrogat si són aqueste[s] [1] es sues [5V] conffessions y judicials respostes: E dix que sí.

[11R] Testimonis rebuts en lo lloch de Çueca per part e instància del honorable en Juan Avellà, procurador fiscal del il·lustríssimo señor mestre de Muntesa en lo present lloch de Çueca, sobre los capítols de la dita denunciació e criminal acusació per aquell posada a XV dies dels propassat mes de mars contra en Juan Navarro, flaquer, delat e denunciat, los quals dits testimonis són del thenor següent:

\section{Die VIIII ${ }^{\circ}$ mensis apprilis anno a nativitate Domini MDLXXVIII.}

Lo honorable en Vicent Cabañes, sastre, habittador del [pre]sent lloch de Çueca, de edat de vint-y-sis anys p[och] més o meñys, testimoni produhït e [donat] per part e instància del dit procurador fiscal, lo [qual] dit testimoni, jura, etc., dir veritat, etc.

E primerament, dicti juramenti virtute, és estat interrogat ell, dit testimoni, sobre l'onzé capítol del a dita scriptura, obmesos los precedents, lo qual davant li [fonch] lest e donat a entendre segons se pertañy:

E dix q[ue] [ell], dit testimoni, està en recort que diverses vegades ha vist tenir en la dita sala eo cort forment e arròs, e, senyaladament, se recorda e[1]1, dit testimoni, que en lo añy propassat [te]nien los magnifichs jurats del present lloch forment en un oró de dita sala eo cort.

XII Ítem super duodecimo: 
[E] dix que ell, dit testimoni, bé està en recort haver vist [11V] los dits dos arm[aris] en la dita sala, però ell, dit testimoni, no sab que en dits armaris y haja libres, ni registres ni lo que en aquell y ha.

XIIII Ítem super decimo quarto obmisso precedenti, etc.:

E dix que ell, dit testimoni, està en recort que ha hoït dir públicament, en lo present lloch de Çueca, que lo dit Juan Navarro és estat attrobat de nit, dins la entrada de la sala eo cort del present lloch e que en lo pañy del cadenat de dita porta era estada attrobada una clau, e que hauria fet fer aquella lo dit Juan Navarro. E açò ha hoït dir ell, dit testimoni, públicament e ab veu e fama pública en lo present lloch de Çueca.

Generaliter, etc.: Et ad omnia dixit non.

[Ulti]mo, etc.: E dix que qui tinga justícia.

[In]terrogat si sab scriure: E dix que sí.

Iniunctun, etc.

Vicente Cabañes

\section{Dictis die et anno.}

Lo honorable en Micolau Ribes, sastre habittador del present lloch de Çueca, de edat de trenta-s[e]t añys poch més o meñys, testimoni lo qual jura, etc., dir veritat, etc.

E primerament és estat interrogat ell, dit testimoni, [12R] sobre lo onzén capítol de la dita scriptura obmesos los precedents, etc.:

E dix que ell, dit testimoni, està en recort haver vist en lo añy propassat que en la entrada de dita sala y havia huns orons, però no està en recort ell, dit testimoni, haver vist lo que en aquells hi havia, bé és veritat que, en lo porche de dita sala eo cort, ha vist diverses vegades ell, dit testimoni, mesurar forment.

XII Ítem, super duodecimo:

E dix que ell, dit testimoni, bé està en recort haver vist que en la dita sala y ha dos armaris, però no ha vist ell, dit testimoni, ni sab [...] aquells hi ha.

[XIIII] ${ }^{10}$ Ítem, super decimoquarto obmisso preced[entibus, etc.]:

E dix que ell, dit testimoni, ha hoït dit públicament en lo present lloch de Çueca que lo dit Juan Navarro era estat attrobat en la entrada de la sala eo cort del present lloch, de nit, e que era estada att[ro]bada una clau faitisca en lo pañy de la porta de dita sala.

Generaliter, etc.: E dix a tot que no.

Ultimo vero, etc.: E dix que qui tinga justícia.

Interrogat si sab scriure: E dix que no.

Iniunctum, etc.

[12V] Dictis die et anno.

Lo honorable en Berthomeu Reverter, sastre, habittador del present lloch de Çueca, de edat de trenta-añys poch més o meñys, testimoni produhit e donat per part e instància del procurador fiscal, lo qual jura, etc., dir veritat, etc.

10 Hem reconstruït aquesta xifra romana tal com la representa l'escrivà al llarg del text. 
[X]IIII E primerament és estat interrogat ell, dit testimoni, sobre lo quatorzen capítol de la dita scriptura obmesos los precedents, etc.:

E dix que està en recort ell, dit testimoni, que trobant-se pochs dies aprés del dia e festa de $\mathrm{Na}$ [dal] propassat, en la vila de Corbera, hoí dir ell, testimoni, a huna morisca nomenada Aruhela, muller de Aruhel, nou convertit, que era estat attrobat lo dit Juan Navarro, flaquer, en la entrada de la sala eo cort del present lloch. E que havien attrobat en lo pañy de la porta de dita sala huna clau faitisca. E aprés, públicament, $\mathrm{h}[\mathrm{u}]$ ha hoït dir ell, dit testimoni, en lo present lloch de Çueca.

Generaliter, etc.: E dix a tot que no.

Ultimo vero, etc.: E dix que la part que tinga justícia.

Interrogat si sab scriure: $\mathrm{E}$ dix que no.

Iniunctum, etc.

[13R] Die XIII ${ }^{\circ}$ mensis apprilis anno a nativitate Domini MDLXXVIII.

Lo honorable en Pedro de Alçó, sastre, habittador del present lloch de Çueca, testimoni produhit e donat per part $\mathrm{e}$ instància del dit procurador fiscal, lo qual dit testimoni jura, etc., dir veritat, etc.

XI E, primerament, és estat interrogat ell, dit testimoni, super undecimo obmisso precedentibus, etc.:

E dix que no y sab res.

XII İtem, super duodecimo:

E dix que ell, dit testimoni, bé està en recort haver [vist] los dits dos armaris dalt la dita sala, però no [sap] ell, dit testimoni, lo que està dins los dits arma[ris].

[XIIII] İtem, super decimoquarto obmisso precedenti[bus, etc.]:

E dix que ell, dit testimoni, no y sap res.

Generaliter, etc.: E dix a tot que no.

Ultimo, etc.: E dix a tot que qui tinga justícia.

Pedro de Alçó

Iniunctum, etc.

\section{Dictis die et anno.}

Lo honorable en Damià Frígola, testimoni produhit e donat per part e instància del dit procurador fiscal, lo qual dit testimoni jura, etc., dir veritat, etc.

E primerament és estat interrogat ell, dit testimoni, sobre lo onzé capítol de la dita scriptura obmesos los [13V] precedents, etc.:

E dix que ell, dit testimoni, està en recort haver vist dins les parets de dita sala haver-hi forment e, senyaladament, en lo añy propassat que tenien los magnifichs jurats del present lloch forment en un oró. E ha molts añys que axí mateix hi havia de marcar lo sastre hun poch de forment, lo qual se vengué a Gaspar de Corcó.

XII Ítem, super duodecimo:

E dix que és veritat que en dita sala y ha dos armaris e que ell, dit testimoni, ha hoït dir que en aquells y ha llibres, però no sab ell, dit testimoni, de certa sciència lo que en aquelles hi ha.

[XIIII] Ítem, super decimoquarto obmisso precedenti, etc.:

E dix que ell, dit testimoni ha hoït dir públi[cament] [en] lo present lloch de 
Çueca que lo dit en Juan [...] estat attrobat a la porta de la sala del present lloch de nit, e ab la porta uberta, e en lo pañy o cadenat de aquella era estada attrobada una clau faytisca. E que per ço, lo havia posat lo magnífich justícia del present lloch en la presó, al dit Juan Navarro.

Generaliter, etc.: E dix a tot que no.

Ultimo, etc.: E dix que qui tinga justícia.

Interrogat si sab scriure: E dix que no.

[creu]

Iniunctum, etc.

[14R] Pretterea vero die intitulato octavo mensis apprilis anno quo suppra a nativitate Domini millesimo quingentesimo.

Davant la presència del magnifich justícia del present lloch de Çueca y en cort sua comparegué personalment lo dit en Juan Navarro e posà la scriptura de capítols del thenor immediate següent:

\section{Ihesus}

Deffenent y contradient Joan Navarro, flaquer del present lloch de Çueca, a la que $\mathrm{s}$ diu denunciació contra aquell posada davant de vostra magnificència per part del procurador fiscal, com millor pot $\mathrm{y}$ deu, y per a donar son descàrrech y desculpa diu e posa lo que segueix:

[I] E primerament diu e posa que ressa ésser ver [...] expressament se nega ell, dit Joan Navarro, proposant, haja comés delicte tal per lo qual sia incorregut en pena alguna corporal o pecuniària, e que haja falcifficat clau per a obrir la porta de la sala e cort del present lloch. E que lo dit procurador fiscal tinga provada sa intenció eo modo quo probari debet a fi ut possit sequi condempnatio. E axí és ver e mostràs clarament per lo que·s segueix:

[II] [...] diu e posa lo que provar entén non se astringens [...] que ell, dit Joan Navarro, proposant en sa condició, és home honrrat, abonat y affidat y de conffiança, y per tal tengut, conegut y reputat. Eaxí és ver, publich e nottori.

[14V] III Ítem, diu ut suppra que lo dit proposant és bon crestià, temerós de Nostre Señor, persona de crèdit, que ha acostumat de donar bon compte del que li és estat acomanat sens que y haja hagut clamaters. Y senyaladament és home que, des de que està en lo present lloch de Çueca, no ha comés ni perpetrat alguna manera de delicte, ni és estat inffamat per rahó de aquell. Y és estat tengut $\mathrm{y} \cdot 1$ tenen comunament per home de bona vida, fama e conversació. E axí és ver.

[IIII] Ítem, diu ut suppra que dins les portes de la cort y sala del present lloch, la nit del gloriós sent Estheve que fonch lo endemà de Nadal propassat, y dies enans y de llavors ensà, no y ha hagut forments ni altres grans alguns. E axí és ver.

[V] Ítem, diu ut prius que la dita nit de sant [...] anant passejant per lo present lloch lo dit proposant y arribat que fonch al porche a hon està la porta de la dita cort e sala, trobà aquella uberta. Y s'acostà y regonegué si y havia algú de dins en la entradeta $\mathrm{y}$, no trobant algú, se posà a orinar. Y horinat $\mathrm{q}[\mathrm{u}] \mathrm{e}$ hagué se'n tornà a exir $\mathrm{y}$ trobà que en lo pañy que està a la part de fora de les portes hi havia una clau $y$, perquè 
és amich de Colàs Assenssi qui té càrrech de obrir y tancar les portes de la dita cort y sala, pensant que per descuyt lo dit Colàs Assenssi se hauria deixat dites portes ubertes, perquè no hagués de rebre alguna repprehensió, detterminà [15R] de tancar bonico les dites portes y donar la dita clau al dit Colàs Assenssi, y advertir-lo que no $\cdot \mathrm{s}$ descuydàs de les dites portes. Y estant axí tancant lo dit proposant les sobredites portes, arribà lo magnifich justícia del present lloch. E axí és ver.

VI Ítem, diu ut suppra que ressa ésser ver y, per ço, expressament se nega que ell, dit proposant, hagués dit la dita nit de sant Estheve gloriós, quant arribà lo dit magnifich justícia a la porta de la dita cort y sala, o ans o aprés, que la clau que havia trobat en lo pañy de la dita porta, la hagués acomanada Colàs Assenssi a ell, dit propos[sant]. E axí és ver.

[VII] Ítem diu ut prius que ell, dit proposant, [...] [m]olta amistat ab lo dit Colàs Assenssi y per [...] de enuig delliberà lo dit proposant de pendre la dita clau que trobà en lo dit pañy y donar-la al dit Colàs Assenssi, pensant-se que aquell se hauria deixat ubertes les portes de la dita cort e sala. E axí és ver.

VIII Ítem, diu ut suppra que lo d[it] magnifich justícia trobat que hagué al dit proposant la dita nit de [s]ant Estheve a [1] a porta de la dita cort y sala ab la dita clau, lo deixà anar y aprés de alguna estona lo prengué y li demanà que li donàs la dita clau, y lo dit proposant, sens diffi[c]ultat la y donà. E axí és ver.

[15V] VIIII Ítem, diu ut suppra que persones de bon juhí diran e testifficaran que tenen per cosa molt certa e indubitada que si lo dit proposant haguera portat la dita clau faytisca per a obrir les portes de la dita cort y sala per algun mal deliber, que arribant lo dit magnifich justícia a les dites portes y trobant al dit proposant junct de aquelles que haguera llançat en terra la dita, puix li era fàcil al dit proposant llançarla. E que no havent-la llançada ans havent-la mostrada al dit magnífich justícia, tenen per molt cert e indubitat ser ver que lo dit proposant trobà la dita clau en lo dit pañy, e que no la portà indubitadament ni en altra manera. E axí és ver.

$[\mathrm{X}]$ Ítem, diu ut suppra que ressa ésser ver [...] expressament se nega que la dita nit de sent Estheve propassat, o dies enans, [...] faltat algunes coses de la dita cort y sala, com són forments y altres grans, o scriptures, o actes, o altres coses algunes. E axí és ver.

Ex quibus et aliis, clarament se mostra lo descàrrech e desculpa del dit proposant y lo procurador fiscal, restar improvat pre maxime no havent produhit per sa part sinó un sol testimoni a la deposició del qual, ultra de no tenir conteste, no's pot donar-se ni crehensa de justícia per patir [16R] en sa persona objectes molt nottoris, dels quals per ésser tan clars no y ha perquè fer-ne indivídua menció. Y per ço ell, dit proposant, venit absolvedus ab impentis e axín requir e demana ell, dir proposant, ésser fet, pronunciat e sentenciat per vostra magnificència per ésser axí confforme a justícia compliment de la qual, etc., implorant, etc.

Sobre los quals ${ }^{11}$ capítols requir que testimonis li sien rebuts cum partes iniunctione, etc., alii.

11 Al ms. cuas. 
E posada la dita scriptura de conttestació, fonch feta la provisió del thenor següent:

Recipientur testes ut requiritur dum modo [...] non rettardetur processus et inquisitio.

Dicto die.

Retulit Colàs Assenssi, missatge ell, hui, haver instat dita scriptura e provisió de aquella al dit en Juan Avellà, procurador fiscal, personalment. Testimonis rebuts en lo lloch de Çueca per part e instància del dit en Juan Nava[r]ro, flaquer, sobre los capítols de la dita scriptura per aquell posada en calendari de huyt dies dels presents mes e añy, los quals dits testimonis són del thenor immediate següent:

\section{[16V] Die XII ${ }^{\circ}$ mensis apprilis anno a nativitate Domini MDLXXVIII.}

Lo honorable en Francés Gurrea, llaurador, habittador del present lloch de Çueca, de edat de cinquanta añys poch més o meñys, testimoni produhit e donat per part $\mathrm{e}$ instància del dit en Juan Navarro, flaquer, lo qual dit testimoni jura, etc., dir veritat, etc.

E primerament és estat interrogat ell, dit testimoni, sobre lo segon capítol de la dita scriptura, lo qual davant li fonch lest e donat a entendre segons se pertañy, obmés lo precedent, com sobre aquell no sia stat produhit ni donat, ni per conssegüent interrogat:

E dix que ell, dit testimoni, té e reputa al dit Juan Navarro, en dit capítol mencionat, per home honrat, abonat e de molta conffiança. E per tal lo ha vist te[nir] e reputar en lo present lloch de Çueca comunament.

III Ítem super tercio:

E dix que per lo semblant ell, dit testimoni, té e reputa al dit Juan Navarro per home bon crestià, temerós de Nostre Señor Déu, e per tal qual se conté en lo dit capítol. E no sab ell, dit testimoni, ni ha hoït dir que lo dit Juan Navarro haja comés ni perpetrat delictes alguns en lo present lloch ni en altra part, per rahó dels quals sia estat inffamat. E no res meñys comunament lo ha vist tenir e reputar en lo present lloch de Çueca [17R] per home de bona vida, fama e conversació honesta. E per tal lo té e reputa ell, dit testimoni.

\section{IIII Ítem super quarto:}

E dix que ell, dit testimoni, no sap ni ha hoït dir que dins les portes de la dita cort eo sala del present lloch, hi haja hagut del dia e festa del gloriós sent Estheve, que fonch lo endemà de Nadal propassat, forment ni altres grans, sinó és ara, últimament, que haurà quinze dies poch més o meñys que portaren forment per la universitat del present lloch, e descarregaren-lo e posaren aquell dins la entrada de dita sala eo cort. E aprés ha [hoït] dir ell, dit testimoni, que portaren dit forment a [...] del cambrer del present lloch.

VII Ítem super septimo obmissis precedentibus, etc.:

E dix que ell, dit testimoni, no sab si lo dit Juan Navarro és amich del dit Colàs Assenssi o no, bé és veritat que ha hoït dir ell, dit testimoni, al dit Juan Navarro que lo dit Colàs Assenssi li era amich. E que havent-se trobat lo dit Juan Navarro la dita clau en lo pañy de la porta de la dita sala eo cort, determinà de pendre la dita clau per a restituhir-la e donar-la al dit Colàs Assenssi, missatge, per a guardar-lo de enuig ab los officials. 
Ítem superdecimo obmissis precedentibus, etc.:

[17V] E dix que ell, dit testimoni, no sab ni ha hoï dir que hajen faltat coses ningunes de la dita sala eo cort, del dit dia del gloriós sent Estheve ençà, ni enans del dit dia, ni scriptures algunes o altres actes.

Generaliter, etc.: E dix a tot que no.

Ultimo vero, etc.: E dix que la part que tinga dret e justícia.

Fonch interrogat si sab scriure: E dix que no.

[creu]

Iniunctum, etc.

\section{Dictis die et anno.}

Lo honorable en Francisco Ximénez, çabater, habittador del present lloch de Çueca, de edat de trenta añys poch més o meñys, testimoni produhit e donat per part e instància del dit Juan Navarro, lo qual dit testimoni jura, etc., dir veritat, etc.

E primerament és estat interrogat ell, dit testimoni, sobre lo segon capítol obmés lo precedent, etc.:

E dix que ell, dit testimoni, té e reputa al dit Juan Navarro, flaquer, en dita scriptura mencionat, per home honrat abonat, y de molta fidelitat y conffiança, y per tal lo ha vist tenir e reputar comunament en lo present lloch de Çueca.

III Ítem super tercio:

[E] dix que ell, dit testimoni, axí mateix té e reputa al dit Juan Navarro per home bon crestià, temerós [18R] de Nostre Senyor Déu, e per home de molt crèdit e que tracta sos negocis ab molta fidelitat y sens frau. Y no sab ni ha hoït dir ell, dit testimoni, que ningú se haja clamat de aquell, ni que haja comés ni perpetrat delictes alguns per rahó dels quals sia estat inffamat. E comunament lo ha vist tenir e reputar en lo present lloch per home de bona vida, fama e honesta conversació, e segons que en dit capítol se conté.

IIII İtem super quarto:

E dix que ell, dit testimoni, no sab ni ha vist que dins les portes de la dita sala eo cort hajen acostumat de tenir forment ni altres grans.

VII Ítem super septimo obmissis precedentibus, [etc.]

E dix que no y sab res.

$\mathrm{X}$ Ítem super decimo obmissis, etc.

E dix que no y sab res.

Generaliter, etc.: E dix a tot que no.

Ultimo, etc.: E dix que qui tinga millor dret e justícia.

[creu]

Iniunctum, etc.

Dictis die et anno.

Lo honorable en Juan Baldoví, fill de Juan, llaurador, habittador del present lloch de Çueca, de edat de cinquanta añys $[\mathbf{1 8 V}]$ poch més o meñys, testimoni produhit e donat per part e instància del dit en Juan Navarro, lo qual dit testimoni, jura, etc., dir veritat, etc. 
E primerament és estat interrogat sobre lo segon capítol, etc.:

E dix que ell, dit testimoni, té e reputa al dit Juan Navarro, en dita scriptura mencionat, per home de honra y abonat, y de molta fidelitat y confiança, e per tal lo ha vist tenir e reputar comunament en lo present lloch.

[III] Ítem super tercio:

E dix que ell, dit testimoni, per lo semblant, té e reputa al dit Juan Navarro, flaquer, per home bon crestià, temerós de Déu e persona de crèdit e ben [...] en lo present lloch. E aquell ha acostumat donar bon compte e rahó de lo que ha tractat. E no sab ell, dit testimoni, ni ha hoït dir que aquell haja perpetrat ni comés, en lo present lloch ni en altra part, algun delicte per rahó del qual aquell sia stat inffamat. E comunament lo ha vist tenir e reputar ell, dit testimoni, per home de bona vida, fama e conversació, e per tal com se conté en dit capítol.

IIII Ítem super quarto:

E dix que ell, dit testimoni, té per molt cert que lo dit Juan Navarro és amich del dit Colàs Assenssi, e que no folgara que lo dit Colàs Assenssi tinguera enuig [19R] ni fatiga. E en lo demés no y sab res.

$\mathrm{X}$ Item super decimo obmissis precedentibus, etc.:

E dix que ell, dit testimoni, no sab ni ha hoït dir que hajen faltat de la sala eo cort del present lloch forment ni altres coses, ni actes alguns, ni scriptures ni ans del dit dia del gloriós sent Estheve ençà, ni enans; lo que té per molt cert ell, dit testimoni, que si alguna cosa haguera faltat ho haguera hoït dir ell, dit testimoni, per lo present lloch per ésser com és vehí e casatinent en lo dit e present lloch de Çueca.

Generaliter, etc.: E dix a tot que no.

Ultimo, etc.: E dix que la part que tinga justícia.

Interrogat si sab scriur[e]: E dix que sí.

Johan Baldoví

Iniunc-

tum, etc.

\section{Dictis die et anno.}

Lo honorable en Anthoni Olives, llaurador, habittador del present lloch de Çueca, de edat de quaranta añys poch més o meñys, testimoni produhit e donat per part e instància del dit en Juan Navarro, lo qual dit testimoni, jura, etc., dir veritat, etc.

E primerament és estat interrogat ell, dit testimoni, sobre lo segon capítol de la dita scriptura [19V] obmés lo precedent, etc.:

E dix que ell, dit testimoni, té e reputa al dit en Juan Navarro, en dita scriptura mencionat, per home honrrat, abonat e de mota fidelitat, e llealtat y conffiança, e per tal lo ha vist tenir e reputar ell, dit testimoni.

III Ítem super tercio:

E dix que axí mateix ell, dit testimoni, té e reputa al dit Juan Navarro per home bon crestià, temerós de Déu e per persona de molt crèdit e de molta llealtat. E que és persona que ha acostumat viure en sa casa ab quietut e sens desf[...]dar a ningú. E no sab ell, dit testimoni, que ninguna persona se haja clamat de aquell, ni que aquell haja comés ni perpetrat en lo present lloch de Çueca, ni en altra part, crims o delictes alguns per rahó dels quals aquell sia stat inffamat de crim ni delicte algú. E per tal com ha dit e deposat dessús ell, dit testimoni, lo ha vist tenir e reputar comunament, en lo present lloch de Çueca. 


\section{IIII Ítem super quarto:}

E dix que ell, dit testimoni, no sab ni ha hoït dir que, dins les portes de la dita sala eo cort del present lloch, hi haja hagut del dia e festa del gloriós sent Estheve del present añy ençà, ni molts dies enans, forment ni altres grans [...]ns.

[20R] VII İtem super septimo obmissis precedentibus, etc.:

E dix que no y sab res.

$\mathrm{X}$ Ítem super decimo obmissis precedentibus, etc.:

E dix que ell, dit testimoni, no sab ni ha hoÿt dir que hajen faltat en ningun temps coses algunes de la dita sala eo cort, ni alguns actes ni altres scriptures; lo que té per molt cert ell, dit testimoni, que si haguera faltat que ell, dit testimoni, ho haguera hoït dir, per tenir ell, dit testimoni, sa casa e habitació en lo dit e present lloch de Çueca.

Generaliter, etc.: E dix a tot que no.

Ultimo vero, etc.: E dix q[u]e la part que tinga [justícia].

Interrogat si sab scriu[r]e: E dix que sí.

Antoni Olives

Iniunctum, etc.

\section{Bibliografia}

Ardit, M. (1992). «Els segles XVI, XVII i XVIII.» dins de Història del País Valencià. València: 3 i4.

Badia i Margarit, Antoni M. (1994[1951]). Gramàtica històrica catalana. València: Tres i Quatre.

Barberà, Joan (2018). El català de la Ribera del Xúquer als tombants del segle XVI (15701599). Edició i estudi lingüístic d'onze processos criminals. (Tesi doctoral en dipòsit).

Batlle, Mar (2002). L'expressió del temps compostos en la veu mitjana i la passiva pronominal. Barcelona: PAM.

Bernat, Francesc; Martí , Joan; Massanell,Mar (2000). «Morfologia». Gramàtica històrica catalana II: l'evolució del sistema, mòdul II. Barcelona: Universitat Oberta de Catalunya.

Casanova, Emili (1989). «Les conjuncions finals en català. El cas de per a que.», dins de La Corona d'Aragó i les llengües romàniques. Miscel-lània d'homenatge per a Germà Colon. Tübingen: Gunter Narr Verlag, pp. 187-201.

- (2008). «Germà Colon, anotador lingüístic de textos. Índex d'aportacions etimològiques $\mathrm{i}$ interpretatives a propòsit dels furs». dins d'El deler de les paraules. Les aportacions de Germà Colon a la romanística. A cura d'Emili Casanova i M. Teresa Echenique. València: Universitat de València, pp. 57-103.

CICA = (2009). Corpus Informatitzat del Català Antic (CICA) [en línia].http://www.cica. cat/index.php\#

CIVAL $=(2013)$. Corpus informatitzat del valencià [en línia].http://cival.avl.gva.es/cival/ buscador.jsp

DCVB = Alcover, Antoni M.; Moll, F. de Borja (1962). Diccionari Català-Valencià-Balear . [en línia]. http://dcvb.iecat.net/

DECat = Coromines, J. (1980-2002). Diccionari etimolòic $i$ complementari de la llengua catalana. Barcelona: Curial.

DNV = (2013). AVL. Diccionari Normatiu Valencià [en línia].http://www.avl.gva.es:8080/ dnv/ 
Farreny i Sistach, Maria Dolors (2004). La llengua dels processos de crims a la Lleida del segle XVI. Barcelona: Institut d'Estudis Catalans.

Ferrando, Salvador; Rangel, Noelia (ed.) (2011). Llibre de la Cort del Justicia de Sueca (1457). València: Universitat de València.

Furió, A (1982). Camperols del Páis Valencià. Sueca una comunitat rural a la tardor de l'Edat Mitjana. Valèncià: Institució Alfons el Magnànim.

GNV = Acadèmia Valenciana de la Llengua (2006). Gramàtica Normativa Valenciana . València: AVL.

Martí i Mestre, Joaquim (1994): Llibre d'antiquitats de la seu de València. Barcelona / València: PAM-Universitat de València, (volum II).

Mateu Fontanals, Jaume (2005) «La selecció de l'auxiliar en els verbs intransitius del català antic: alguns aspectes descriptius i explicatius». Caplletra. València: UV, núm. 38, pp. 211-240.

Pérez Saldanya, Manuel (1998). Morfosintaxi Verbal històrica del llatí al català.

València: Universitat de València.

Veny, Joan; Massanell, Mar (2002). Dialectologia catalana. Barcelona: Universitat Oberta de Catalunya.

Veny, J.; Massip, A. (2009). Scripta Eivissenca. Barcelona: IEC.

Veny, J. (2009). Per una història diatòpica de la llengua catalana. Barcelona: Publicacions l'Abadia de Montserrat.

- (2015). Regiment de preservació de pestilència (1348) de Jacme d'Agramont. Barcelona: Publicacions l'Abadia de Montserrat. 